\title{
A study of effect of delayed and early umbilical cord clamping on neonatal haemoglobin status
}

\author{
Jyoti Jaiswal, Krishna Kumar Dehariya, Devina Nagraj*
}

\begin{abstract}
Department of Obstetrics and Gynaecology, Pt. J. N. M. Medical College and Dr. B. R. A. M. Hospital, Raipur, Chhattisgarh, India
\end{abstract}

Received: 26 March 2021

Revised: 02 May 2021

Accepted: 03 May 2021

\author{
*Correspondence: \\ Dr. Devina Nagraj, \\ E-mail: dvna1008@gmail.com
}

Copyright: () the author(s), publisher and licensee Medip Academy. This is an open-access article distributed under the terms of the Creative Commons Attribution Non-Commercial License, which permits unrestricted non-commercial use, distribution, and reproduction in any medium, provided the original work is properly cited.

\begin{abstract}
Background: Delayed cord clamping has been supported by physician because it allows for physiological transfer of blood from placenta to the infant and thus permits placenta to newborn transfusion and results in an increased neonatal blood volume at birth. At present there is no standard definition of delayed cord clamping. Clamping time varies significantly between studies and a wide range of parameters were used for clamping of cord.

Methods: This was an observational study conducted in a public hospital among 200 uncomplicated full-term pregnancies where 100 each were present in early cord clamping (ECC) and delayed cord clamping (DCC) groups respectively and neonatal haematological parameters studied according to different cord clamping times.

Results: There was a significant increase of mean haemoglobin level from 14.8 to $16.0 \mathrm{~g} / \mathrm{dl}$ from 15 secs to 60 secs and gradual increase of mean haemoglobin level from 16.2 to $16.8 \mathrm{~g} / \mathrm{dl}$ from $60 \mathrm{secs}$ to $180 \mathrm{secs}$. There was a highly significant difference between ECC and DCC groups regarding mean haemoglobin level and MCH values. MCV and $\mathrm{MCH}$ values were also significantly different in both the groups.

Conclusions: We concluded in this study that delayed cord clamping, resulted in improved haemoglobin and other haematocrit levels specially when cord was clamped after first 60 secs. Delayed clamping also reduced the prevalence of neonatal anaemia at 2 days of age. In terms of maternal outcomes, delayed umbilical cord clamping did not increase the risk of postpartum haemorrhage or the need for blood transfusion.
\end{abstract}

Keywords: Delayed cord clamping, Neonatal haemoglobin, Newborn anaemia, Observational study

\section{INTRODUCTION}

The blood circulation continues between the baby and the mother after birth through the umbilical vein and arteries for some time. So, the duration after which the cord is clamped will have significant effects on infant blood volume at birth and thereby contributing to the infant body iron. Different terms are being used to define the time of cord clamping. Early or immediate clamping is most commonly defined as when the cord is clamped within the first 10-15 seconds after delivery of the infant. Delayed or late cord clamping is most frequently defined as clamping that occurs 2 or 3 minutes after delivery of the infant, or at the point at which cord pulsations cease. ${ }^{1}$ It was seen that blood flows through the umbilical arteries during the first 20-25 seconds after birth; in contrast, in the umbilical vein, blood flow continues from the placenta to the infant for up to 3 minutes after delivery. Thus, not clamping the cord immediately after delivery provides a placental transfusion to the infant.

In the past, as part of an active management strategy, the umbilical cord was clamped immediately after birth of the infant, usually within first 30 seconds after birth, regardless of whether the cord pulsations have ceased. A Cochrane review in 2013 concluded that DCC (between 
one and three minutes after birth) is likely to be beneficial as long as access to treatment for jaundice requiring phototherapy is available. $^{2}$

The American college of obstetricians and gynaecologists committee on obstetric practice recommends that in term infants, delayed umbilical cord clamping increases haemoglobin levels at birth and improves iron stores in the first several months of life, which may have a favourable effect on developmental outcomes. Also, in preterm infants DCC results in improved transitional circulation, better establishment of red blood cell volume and decreased need for blood transfusion. Also, it leads to lower incidence of necrotizing enterocolitis and intraventricular haemorrhage and does not increase the risk of postpartum haemorrhage. ${ }^{3}$

\section{Aim}

The aim of the study was to look for any effect of timing of cord clamping on neonatal outcome with respect to haemoglobin status.

\section{Objectives}

The objective of the study was to note the timing of cord clamping and evaluate neonatal hemoglobin status and hematocrit parameters in neonates.

\section{METHODS}

The study was an observational study. The study was conducted in the department of obstetrics and gynaecology, Pt. J.N.M. medical college and Dr. B. R. A. M. hospital, Raipur. The study was conducted from July 2017 to June 2018. A total of 200 pregnant women, scheduled for ECC and DCC were selected for the study.

\section{Inclusion criteria}

Healthy pregnant women with singleton pregnancy between 37-41 weeks were included in the study.

\section{Exclusion criteria}

All abnormal pregnancies and labor (pre-eclampsia, diabetes, sign of PROM, sign of infection, severe anemia, multiple gestations, meconium-stained liquor) were excluded. Also, pregnant women with medical disorder like DM, HTN, jaundice, severe anemia, renal disorders and pregnancies with fetal congenital malformation syndrome or other congenital diseases were not included. Instrumental deliveries were also excluded.

\section{Ethical clearance}

The study was approved by the institutional scientific committee and institutional ethical committee of J. N. M medical college, Raipur to use human subjects in the research study.

\section{Statistical analysis}

Data was collected by using a structure proforma data entered in MS excel sheet and analyzed by using SPSS 16.0 version IBM USA. Qualitative data was expressed in terms of proportions. Quantitative data was expressed in terms of mean and standard deviation. Comparison of mean and SD between two groups was done by using unpaired $\mathrm{t}$ test to assess whether the mean difference between groups is significant or not. Descriptive statistics of each variables were presented in terms of mean, standard deviation. A $\mathrm{p}<0.05$ was considered as statistically significant whereas a $\mathrm{p}<0.001$ was considered as highly significant.

\section{Study procedure}

In our institute, Dr. B. R. A. M. hospital practice regarding timing of cord clamping after delivery was not uniform and no time limit for cord clamping was defined as departmental policy before the start of the study. Few members used to clamp the cord immediately after birth of baby, few did it early within one minute while few clamped it after one minute.

All the full-term low risk pregnant patients after taking the consent were included and according to the time of cord clamping were divided into ECC and DCC groups.

Data was collected by a preformed proforma from women and blood test were conducted on the infants between 48-72 hours after birth and results were analysed.

\section{RESULTS}

Majority of the cases were between 38-39 weeks of gestation. Cases in both the groups were demographically matched.

Majority of cases were having BMI between 18.5-24.9 (89\%). There was no significant difference between ECC and DCC group.

Maximum cases were of 21 to 30 years in both groups. There was no significant difference between ECC and DCC groups based on age.

Cases were demographically matched and maximum cases were either $\mathrm{P} 1$ or $\mathrm{P} 2$.

There was not much significant difference in percentage of cases between ECC and DCC group with regards to amount of blood loss in vaginal deliveries and LSCS.

There was a significant increase of mean haemoglobin level from 14.8 to $16.0 \mathrm{~g} / \mathrm{dl}$ from 15 to 60 seconds. There was gradual increase of mean haemoglobin level from 16.2 to $16.8 \mathrm{~g} / \mathrm{dl}$ from 60 to 180 seconds. There was a statistically significant difference in haemoglobin level 
between ECC and DCC. Maximum cases were of haemoglobin level 14-16 g/dl in both groups.
Overall maximum cases were having haemoglobin level upto $16 \mathrm{~g} / \mathrm{dl}$ in ECC group (92\%).

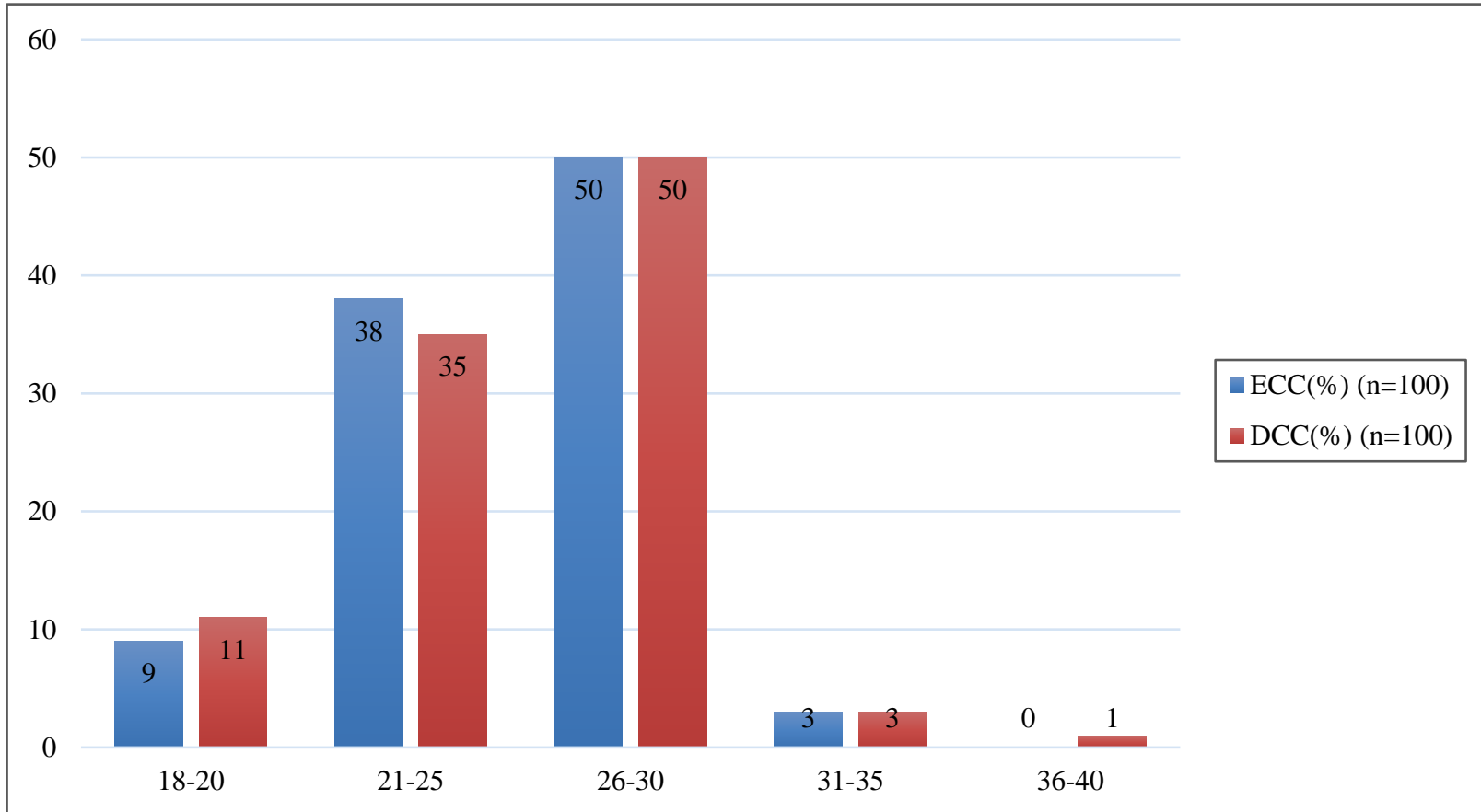

Figure 1: Distribution of cases in different age groups.

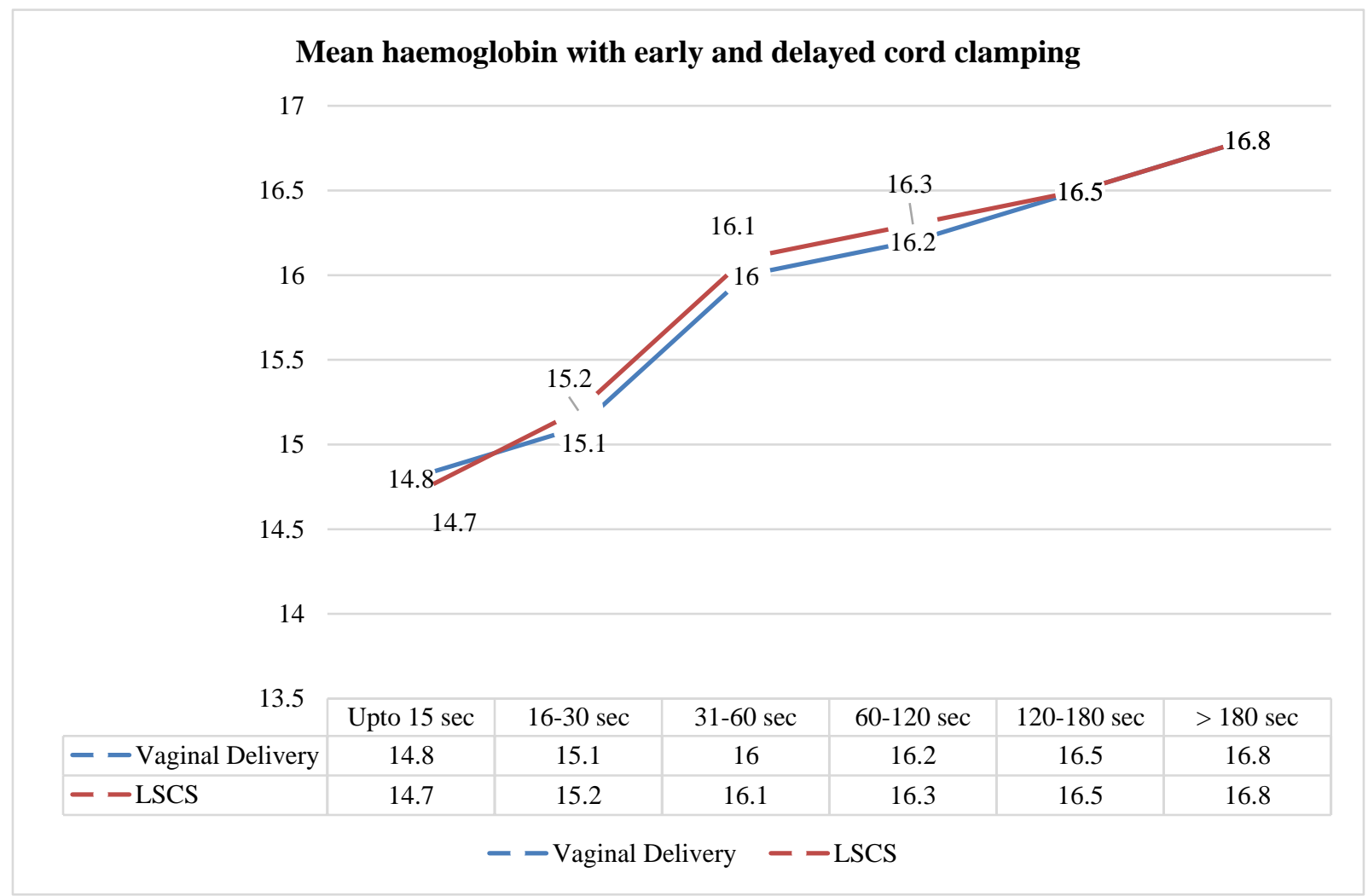

Figure 2: Mean haemoglobin in early and delayed cord clamping group. 


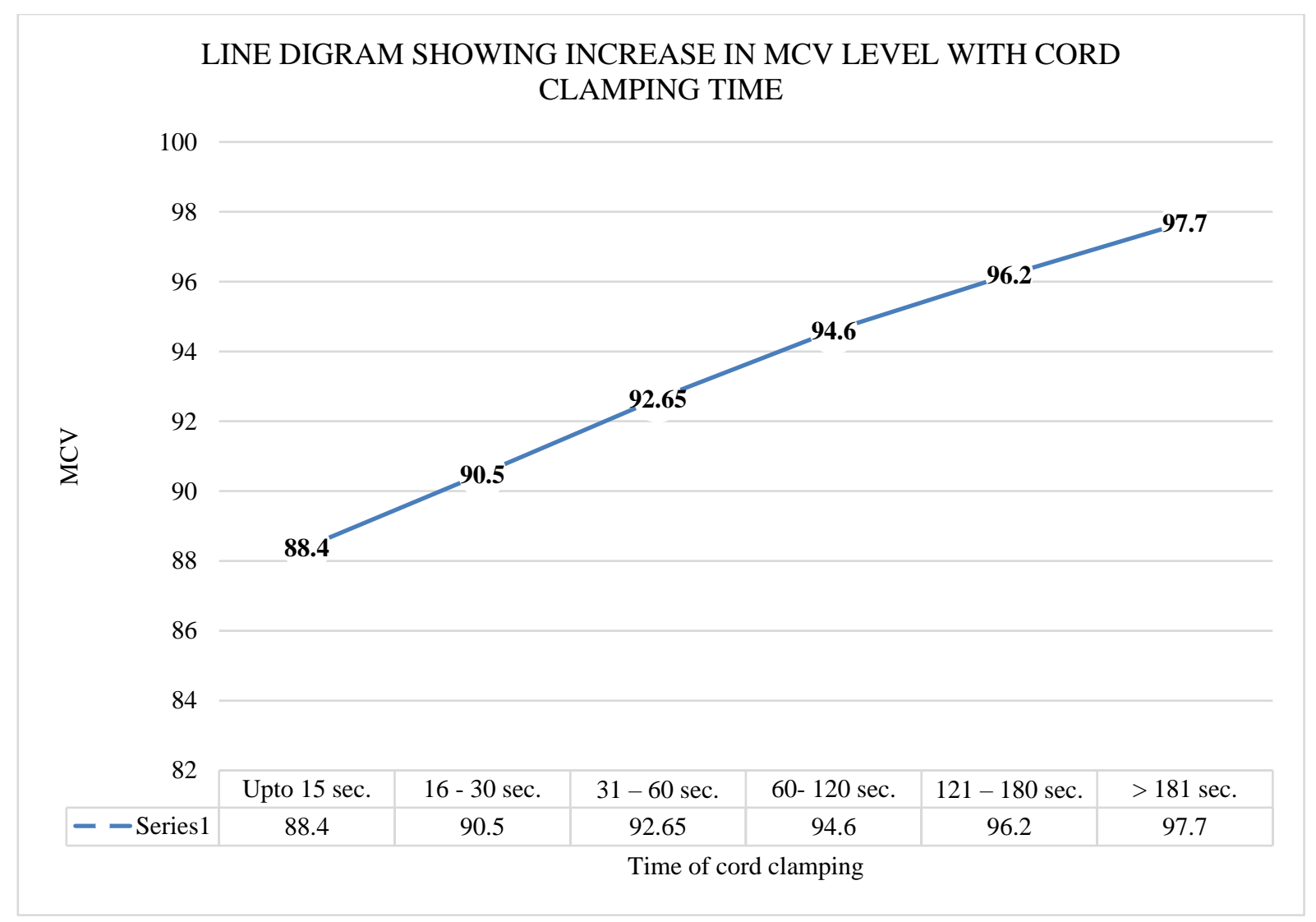

Figure 3: Relation of MCV level in ECC and DCC.

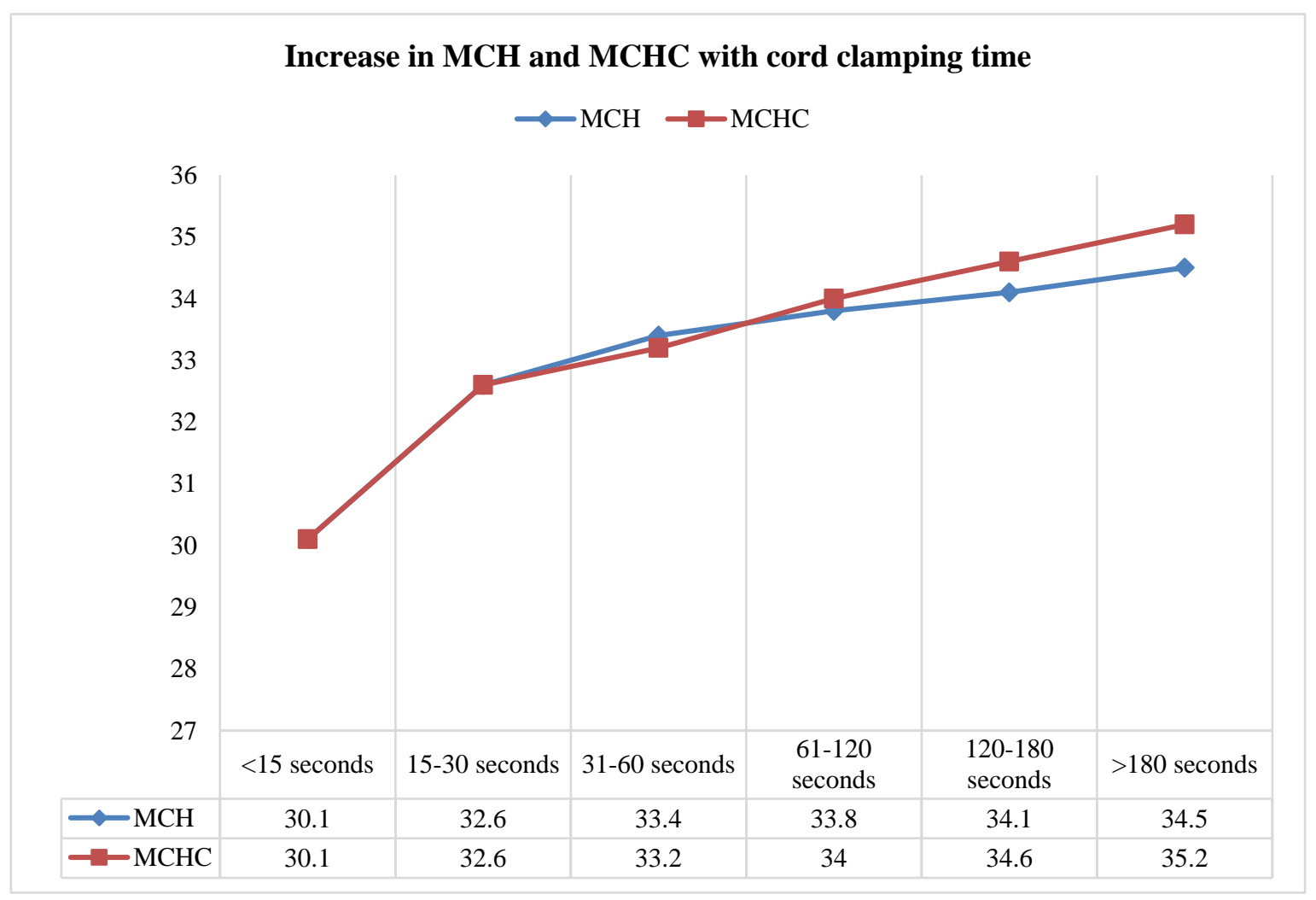

Figure 4: Relation between MCH and MCHC with cord clamping time. 
Table 1: Distribution of cases according to parity.

\begin{tabular}{|c|c|c|c|c|}
\hline S. no. & Parity & $\operatorname{ECC}(\%)(\mathrm{n}=100)$ & $\operatorname{DCC}(\%)(\mathrm{n}=100)$ & $P$ value \\
\hline 1 & $\mathrm{P}_{1}$ & 26 & 30 & \multirow{4}{*}{$\mathrm{P}=0.46$} \\
\hline 2 & $\mathrm{P}_{2}$ & 36 & 28 & \\
\hline 3 & $\mathrm{P}_{3}$ & 24 & 22 & \\
\hline 4 & $\mathrm{P}_{4}$ & 14 & 20 & \\
\hline
\end{tabular}

Table 2: Distribution of cases according to weeks of gestation.

\begin{tabular}{|c|c|c|c|c|c|}
\hline S. no. & Weeks of gestation & $\operatorname{ECC}(\%)(n=100)$ & $\operatorname{DCC}(\%)(n=100)$ & $P$ value & Mean \pm SD \\
\hline 1 & $37-37.6$ & 20 & 26 & \multirow{5}{*}{$\mathrm{P}=0.27$} & \multirow{5}{*}{$38.68 \pm 1.05$} \\
\hline 2 & $38-38.6$ & 30 & 24 & & \\
\hline 3 & $39-39.6$ & 30 & 30 & & \\
\hline 4 & $40-40.6$ & 16 & 14 & & \\
\hline 5 & $\geq 41$ & 4 & 6 & & \\
\hline
\end{tabular}

Table 3: Distribution of cases according to BMI.

\begin{tabular}{|lllll|}
\hline S. no. & BMI & ECC $(\%)(n=100)$ & DCC $(\%)(\mathbf{n}=\mathbf{1 0 0})$ & P value \\
\hline $\mathbf{1}$ & $<18.5$ & 2 & 2 & 0.6521 \\
\hline $\mathbf{2}$ & $18.5-24.9$ & 88 & 90 \\
\hline $\mathbf{3}$ & $\geq 25$ & 10 & 8 & - \\
\hline $\mathbf{4}$ & $\geq 30$ & - & \multicolumn{2}{c}{} \\
\hline
\end{tabular}

Table4: Distribution of cases in ECC and DCC group according to time of cord clamping.

\begin{tabular}{|c|c|c|c|c|c|c|}
\hline \multirow{2}{*}{$\begin{array}{l}\text { Mode of } \\
\text { delivery }\end{array}$} & \multicolumn{3}{|c|}{$\begin{array}{l}\text { Timing of cord clamping in ECC ( } n=100) \text { (in } \\
\text { seconds) }\end{array}$} & \multicolumn{3}{|c|}{$\begin{array}{l}\text { Timing of cord clamping in DCC ( } \mathrm{n}=100) \text { (in } \\
\text { seconds) }\end{array}$} \\
\hline & $<15$ & $16-30$ & $31-60$ & $61-120$ & $121-180$ & $>180$ \\
\hline Vaginal & 20 & 15 & 13 & 16 & 15 & 21 \\
\hline LSCS & 08 & 24 & 20 & 14 & 18 & 16 \\
\hline Total & 28 & 39 & 33 & 30 & 33 & 37 \\
\hline
\end{tabular}

Table 5: Distribution of patients according to cord clamping amount of intrapartum blood loss.

\begin{tabular}{|llllll|}
\hline S. no. & $\begin{array}{l}\text { Amount of } \\
\text { blood loss } \\
\text { (in ml) }\end{array}$ & ECC (n=48) & Vaginal (\%) & LSCS (\%) & VCC (n=52) \\
\hline $\mathbf{1}$ & $<500$ & $40(83.3)$ & $06(11.5)$ & $40(76.9)$ & LSCS (\%) \\
\hline $\mathbf{2}$ & $>500-1000$ & $06(12.5)$ & $41(78.8)$ & $06(11.5)$ & $35(72.9)$ \\
\hline $\mathbf{3}$ & $>1000$ & $02(4.2)$ & $05(9.6)$ & $06(11.5)$ & $05(10.4)$ \\
\hline
\end{tabular}

Table 6: Number of cases according to haemoglobin level in ECC and DCC group.

\begin{tabular}{|lllllll|}
\hline S. no. & $\begin{array}{l}\text { Hemoglobin } \\
\text { level }\end{array}$ & ECC $(\mathbf{n}=\mathbf{1 0 0})$ & $\begin{array}{l}\text { Hemoglobin } \\
(\text { mean } \pm \text { SD })\end{array}$ & DCC $(\mathbf{n}=\mathbf{1 0 0})$ & $\begin{array}{l}\text { Hemoglobin } \\
(\text { mean } \pm \text { SD })\end{array}$ & P value \\
\hline $\mathbf{1}$ & Up to 12 & 0 & 0 & 0 & 0 & 0 \\
\hline $\mathbf{2}$ & $12.1-14$ & 25 & $13.2 \pm 1.1$ & 6 & $13.8 \pm 1.2$ & $<0.001$ \\
\hline $\mathbf{3}$ & $14.1-16$ & 67 & $14.8 \pm 1.3$ & 43 & $15.4 \pm 1.4$ & 0.01 \\
\hline $\mathbf{4}$ & $16.1-18$ & 08 & $16.8 \pm 1.2$ & 37 & $17.6 \pm 1.2$ & $<0.001$ \\
\hline $\mathbf{5}$ & $18.1-20$ & 0 & 0 & 14 & $18.6 \pm 1.1$ & 0 \\
\hline
\end{tabular}


Table 7: Relationship of mean haematocrit of ECC and DCC group.

\begin{tabular}{|c|c|c|c|c|}
\hline S. no. & Mean hematocrit parameter & $\begin{array}{l}\mathrm{ECC}(\mathrm{n}=100) \\
(\operatorname{mean} \pm \mathrm{SD})\end{array}$ & $\begin{array}{l}\text { DCC }(n=100) \\
(\operatorname{mean} \pm S D)\end{array}$ & $P$ value \\
\hline 1 & Hemoglobin level & $15.1 \pm 1.2$ & $16.8 \pm 1.5$ & $<0.001$ \\
\hline 2 & $\mathrm{MCV}$ & $98.1 \pm 15.1$ & $99.3 \pm 10.5$ & 0.04 \\
\hline 3 & $\mathrm{MCH}$ & $30.8 \pm 3.2$ & $31.9 \pm 2.4$ & 0.005 \\
\hline 4 & MCHC & $30.9 \pm 3.4$ & $31.5 \pm 1.6$ & 0.05 \\
\hline
\end{tabular}

Only $8 \%$ cases had haemoglobin more than $16 \mathrm{gm} \%$ in ECC group. Only $6 \%$ cases had haemoglobin $<14$ gm\% in DCC group.

$51 \%$ cases had haemoglobin $>16$ gm, 5 in DCC group. $14 \%$ cases had haemoglobin $>18 \mathrm{gm} \%$ in DCC group.

There was highly significant difference between ECC and DCC groups regarding mean haemoglobin level and $\mathrm{MCH}$ values. $\mathrm{MCV}$ and $\mathrm{MCH}$ values were also significantly different in both groups.

\section{DISCUSSION}

The two groups consisted of participants that were demographically matched. It was seen that DCC proved to be beneficial in this study. There was no significant difference between ECC and DCC group in respect to in age, parity, socioeconomic status, literacy and diet.

There was a significant increase of mean haemoglobin level from 14.8 to $16.0 \mathrm{~g} / \mathrm{dl}$ from 15 to 60 seconds. $\mathrm{P}<0.001$ suggesting statistically highly significant. There is gradual increase of mean haemoglobin level from 16.2 to $16.8 \mathrm{~g} / \mathrm{dl}$ from 60 to 180 seconds. $\mathrm{P}$ value is 0.05 .

There were 48 total cases in vaginal delivery in ECC group. Out of them, cord was clamped within 15 seconds in 20 cases $(41.7 \%)$, within 16 to 30 seconds in 15 cases $(31.3 \%)$ and within 31 to 60 seconds in 13 cases $(26.5 \%)$. The mean haemoglobin level was $16.2 \pm 1.3,16.5 \pm 1.5$ and $16.8 \pm 1.2$ respectively in 3 sub-groups of DCC with increase in time duration of cord clamping which was statistically significant. There was significant increase of mean haemoglobin level from 14.8 to $16.0 \mathrm{~g} / \mathrm{dl}$ from 15 to 60 seconds. $\mathrm{P}<0.001$ suggesting statistically highly significant.

There were 52 total cases in vaginal delivery in DCC group. Out of them, cord was clamped within 61-120 seconds in 16 cases $(30.8 \%)$, within 121 to 180 seconds in 15 cases $(28.8 \%)$ and $>180$ seconds in 21 cases $(40.4 \%)$. The mean haemoglobin level was 16.2 \pm 1.3 , $16.5 \pm 1.5$ and $16.8 \pm 1.2$ respectively in 3 sub-groups of DCC with increase in time duration of cord clamping which was statistically significant. There was gradual increase of mean haemoglobin level from 16.2 to 16.8 $\mathrm{g} / \mathrm{dl}$ from 60 to 180 seconds and $\mathrm{p}$ value was 0.05 .
There were 52 total cases in LSCS in ECC group. Out of them, cord was clamped within 15 seconds in 08 cases (15.4\%), within 16 to 30 seconds in 24 cases (46.2\%) and within 31 to 60 seconds in 20 cases $(38.5 \%)$. The mean haemoglobin level was $14.7 \pm 1.3,15.2 \pm 1.1$ and $16.1 \pm 1.2$ respectively in 3 sub-groups of ECC with increase in time duration of cord clamping which was statistically significant. There was highly significant increase in haemoglobin level in different subgroups of ECC group with increasing time of cord clamping (15-60 seconds; 14.7-16.1 gm\%) $(\mathrm{p}<0.001)$.

There were 48 total cases in vaginal delivery in DCC group. Out of them, cord was clamped within 61-120 sec in 14 cases $(29.2 \%)$, within 121 to 180 seconds in 18 cases $(37.5 \%)$ and $>180 \mathrm{sec}$ in 16 cases $(32.7 \%)$. The mean haemoglobin level was $16.3 \pm 1.2,16.5 \pm 1.4$ and $16.8 \pm 1.5$ respectively in 3 sub-groups of DCC with increase in time duration of cord clamping which was statistically significant. There was gradual and significant increase in haemoglobin level with increasing time of cord clamping between different subgroups of DCC (120$180 ; 16.5-16.8 \mathrm{gm} \%)(\mathrm{p}=0.04)$.

In 2010 Shirvani et al assessed maternal haematological status and DCC versus ECC and found that 48 hours after delivery the mean infant haemoglobin (haemoglobin=16.08 gm./dl versus $14.5 \mathrm{gm} . / \mathrm{dl} ; \mathrm{p}<0.001$ ) and haematocrit $(\mathrm{Hct}=47.6$ versus $42.8 ; \mathrm{p}<0.001)$ levels were significantly higher in the delayed clamping group and infants delivered vaginally had significantly more delayed cord clamp times $(>15$ seconds; $\mathrm{p}<0.001)$. These findings were similar to the present study. ${ }^{4}$

In contrast to present study, Ceradas et al in 2010 found that there were no significant differences in mean haemoglobin values, $10.6 \mathrm{~g} / \mathrm{dl} \quad(\mathrm{SD}=1.1) ; 10.8 \mathrm{~g} / \mathrm{dl}$ $(\mathrm{SD}=0.9)$ and $10.7 \mathrm{~g} / \mathrm{dl}(\mathrm{SD}=1.0)$ between groups early, one minute and three minutes, respectively and also found that the prevalence of iron deficiency anaemia (haemoglobin <10.5 g/dl and ferritin <9 mg/l) was 3 times more frequent in early clamping group $(7.2 \%)$ than in three minutes group $(2.4 \%)(\mathrm{RR}=0.30$; IC $95 \%=0.10$ $1.60) .^{5}$

It was the constant and enlightening result of the study that all cases in DCC group had a high haemoglobin and haematocrit values and the picture is very depicted by the graph showing comparison between ECC and DCC 
group. There was highly significant difference between ECC and DCC groups regarding mean haemoglobin level and $\mathrm{MCH}$ values. $\mathrm{MCV}$ and $\mathrm{MCHC}$ values were also statistically significant in both the groups.

In 2015 Ranjit et al found that mean haematocrit were significantly higher in the infants randomized to DCC group. The haematocrit on day 1 was also significantly higher in the DCC group $(50.8 \pm 5.2 \%$ versus $58.5 \pm 5.1 \%$, $\mathrm{p}=0.00$ ) and observed that DCC group required significantly longer duration of phototherapy $(55.3 \pm 40.0$ hours versus $36.7 \pm 32.6$ hours, $\mathrm{p}=0.016$ ) and had a trend towards higher risk of polycythaemia and concluded that delaying the cord clamping by 2 minutes, significantly improves the haematocrit value at birth and this beneficial effect continues till at least 2 nd month of life which was similar to present study. ${ }^{6}$

In 2018 Chiruvolu et al found similar results to present study, that mean haematocrit at birth was significantly higher in the DCC cohort compared with the historic cohort $(49.1 \pm 14.9$ versus $45.7 \pm 15.7 ; p=0.01)$. There were no differences in the incidence of phototherapy or NICU LOS between groups. ${ }^{7}$

Also, in 2018 Fogarty et al observed that delayed clamping reduced the incidence of low Apgar score at 1 minute, but not at 5 minutes and did not reduce the incidence of intubation for resuscitation, admission temperature, mechanical ventilation, intraventricular haemorrhage, brain injury, chronic lung disease, patent ductus arteriosus, necrotizing enterocolitis, late onset sepsis or retinopathy of prematurity. Delayed clamping increased peak haematocrit by 2.73 percentage points (95\% confidence interval=1.94-3.52; $\mathrm{p}<0.00001)$ and reduced the proportion of infants having blood transfusion by $10 \%$ (95\% confidence interval=6-13\%; $\mathrm{p}<0.00001){ }^{8}$

The limitation of this study was that it was conducted among the low-risk patients and also further studies are needed to explore long term health effects of delayed and early cord clamping among all delivering women.

\section{CONCLUSION}

We conclude in this study that delayed cord clamping, resulted in improved hemoglobin and other hematocrit levels specially when cord was clamped after first 60 seconds. Delayed clamping also reduced the prevalence of neonatal anemia at 2 days of age. Our results suggest that delayed cord clamping has benefits in many aspects and should be considered as standard care for full term deliveries after uncomplicated pregnancies. Term infants appear to derive benefit from delayed umbilical cord clamping therefore, delayed umbilical cord clamping after at least 60 seconds is recommended in term infants except when immediate umbilical cord clamping is necessary because of neonatal or maternal indications. In term infants, delayed umbilical cord clamping increases haemoglobin levels at birth and improves iron stores in early life.

In terms of maternal outcomes, delayed umbilical cord clamping does not increase the risk of postpartum haemorrhage or the need for blood transfusion.

Funding: No funding sources

Conflict of interest: None declared

Ethical approval: The study was approved by the Institutional Ethics Committee

\section{REFERENCES}

1. Chaparro CM. Timing of umbilical cord clamping: effect on iron endowment of the newborn and later iron status. Nutr Rev. 2011;69:30-6.

2. McDonald SJ, Middleton P, Dowswell T, Morris PS. Effect of timing of umbilical cord clamping of term infants on maternal and neonatal outcomes. Cochrane Database Syst Rev. 2013;7:4074.

3. The American College of Obstetricians and Gynecologists Committee. delayed umbilical cord clamping after birth. American J Obstet Gynecol. 2020;136:100-6.

4. Shirvani F, Radfar M, Hashemieh M, Soltanzadeh MH, Khaledi H, Mogadam MA. Effect of timing of umbilical cord clamp on newborns' iron status and its relation to delivery type. Arch Iran Med. 2010;13(5):420-5.

5. Ceriani-Cernadas JM, Carroli G, Pellegrini L, Ferreira M, Ricci C, Casas O, et al. The effect of early and delayed umbilical cord clamping on ferritin levels in term infants at six months of life: a randomized, controlled trial. Arch Argent Pediatr. 2010;108(3):201-8.

6. Ranjit T, Nesargi S, Rao PN, Sahoo JP, Ashok C, Chandrakala BS, et al. Effect of early versus delayed cord clamping on hematological status of preterm infants at 6 week of age. Indian $J$ Pediatr. 2015;82(1):29-34.

7. Chiruvolu A, Daoud Y, Inzer RW. Effect of delayed cord clamping on very preterm twins. Early Hum Dev. 2018;124:22-5.

8. Fogarty M, Osborn DA, Askie L, Seidler AL, Hunter $\mathrm{K}$, Lui $\mathrm{K}$, et al. Delayed vs early umbilical cord clamping for preterm infants: a systematic review and meta-analysis. Am J Obstet Gynecol. 2018;218(1):1-18.

Cite this article as: Jaiswal J, Dehariya KK, Nagraj D. A study of effect of delayed and early umbilical cord clamping on neonatal haemoglobin status. Int J Reprod Contracept Obstet Gynecol 2021;10:2268-74. 